\title{
AN EFFICIENT COOLING LOOP FOR CONNECTING CRYOCOOLER TO A HELIUM RESERVOIR
}

\author{
C.E. Taylor, C S. R. Abbott, D. Leitner, M. Leitner, C.M. Lyneis \\ Lawrence Berkeley National Laboratory, Berkeley, California, 94720, USA
}

\begin{abstract}
The magnet system of the VENUS ECR Ion Source at LBNL has two 1.5-watt cryocoolers suspended in the cryostat vacuum. Helium vapor from the liquid reservoir is admitted to a finned condenser bolted to the cryocooler $2^{\text {nd }}$ stage and returns as liquid via gravity. Small-diameter flexible tubes allow the cryocoolers to be located remotely from the reservoir. With 3.1 watts load, the helium reservoir is maintained at $4.35 \mathrm{~K}, 0.05 \mathrm{~K}$ above the cryocooler temperature. Design, analysis, and performance are presented.
\end{abstract}

\section{VENUS MAGNET SYSTEM}

VENUS (Versatile ECR ion source for NUclear Science) is a next generation superconducting ECR ion source, designed to produce high current, high charge state ions for the 88-Inch Cyclotron at the Lawrence Berkeley National Laboratory. VENUS also serves as the prototype ion source for the RIA (Rare Isotope Accelerator) front end. The magnetic confinement configuration consists of three superconducting axial coils and six superconducting radial coils in a sextupole configuration. The nominal design fields of the axial magnets are $4 \mathrm{~T}$ at injection and $3 \mathrm{~T}$ at extraction; the nominal radial design field strength at the plasma chamber wall is $2 \mathrm{~T}$, making VENUS the world's most powerful ECR plasma confinement structure. The magnetic field strength has been designed for optimum operation at $28 \mathrm{GHz}$. The magnet system has been described elsewhere [i,ii]. FIGURE 1 is a mechanical cross section of VENUS showing the magnets, cryostat, iron shielding, and service tower. FIGURE 2 is a schematic illustration of the superconducting coils. 
FIGURE 1. Mechanical drawing of VENUS showing the major components

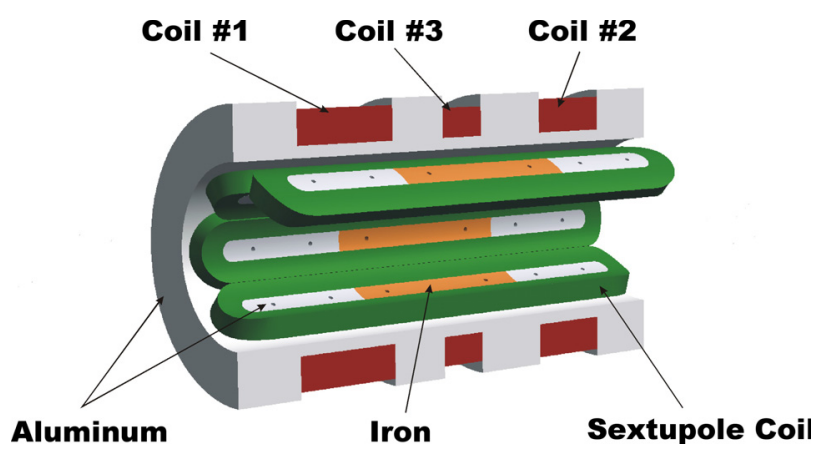

FIGURE 2. Cutout drawing of the coil configuration of the 3rd generation ECR ion source

\section{CRYOGENIC SYSTEM}

A close-fitting tank containing liquid helium encloses the coil assembly. The room temperature bore is $16.5 \mathrm{~cm}$ in diameter. A $10-\mathrm{cm}$. I.D. tube connects the tank to a liquid helium reservoir in the service tower. The two Sumitomo $1.5 \mathrm{~W}$ cryocoolers and the eight current leads are suspended in the service tower vacuum space. A liquid nitrogen tank is provided solely to cool a section of the copper current leads. The cryocooler first stage cools the aluminum heat shield that surrounds the magnet, including the room temperature bore, heat intercepts on the magnet support links, and the warm end of the high Tc current leads.

After the magnet initially has been cooled down with helium from a supply dewar, the helium system is isolated and evaporating helium is condensed by the cryocoolers. The coupling of the cryocoolers to the helium reservoir is the main subject of the paper. 


\section{Heat Input and Current Leads}

A major heat input to the cryogenic system is from the current leads. The two sextupole leads are designed for $600 \mathrm{~A}$ and each of the six solenoid leads are designed for $250 \mathrm{~A}$. Each lead consists of a room-temperature vacuum feed-through, a copper section cooled at the lower end by liquid nitrogen, a second copper section cooled at the lower end by the cryocooler first stage (approximately 45K), and a high Tc section cooled at the bottom end by liquid helium. The eight superconducting magnet leads pass from vacuum through the wall of the helium reservoir and down through the connecting tube to the coil assembly. Each lead section is optimized for minimum heat leak to the cold end. With the full design current on, about $116 \mathrm{~W}$ are removed at $80 \mathrm{~K}$ from the cold end of the first section of copper lead, cooled by liquid nitrogen; about $46 \mathrm{~W}$ are removed at $45 \mathrm{~K}$ from the end of the second section of copper lead, cooled by the cryocooler first stage; and about 0.3 $\mathrm{W}$ at $4.35 \mathrm{~K}$ from the cold ends of the high $\mathrm{T}_{\mathrm{c}}$ leads.

With the current $18 \mathrm{GHz}$ RF system, the operating currents are $110 \mathrm{~A}, 85 \mathrm{~A}$, and 85 $\mathrm{A}$ in the three solenoid windings, and $250 \mathrm{~A}$ in the sextupole. With these currents, the total heat input to the system is $3.1 \mathrm{~W}$ at $4.35 \mathrm{~K}$, and $36 \mathrm{~W}$ at $77 \mathrm{~K}$. At least $1.5 \mathrm{~W}$ of the $4.35 \mathrm{~K}$ heat load is believed to come from a heat leak in the neck tube due to misalignment between the neck tube and $50 \mathrm{~K}$ shield, which occurred during the fabrication of the cryostat.

\section{Heat Transfer Design}

For optimum operation of the VENUS source, it is desired to drive the sextupole coils to the highest achievable magnetic fields. Therefore, the helium bath must be as cold as possible to maximize the critical current. In the initial construction, heat was removed from the helium bath by conduction through flexible copper straps to the cryocoolers; this resulted in an excessive temperature different between the helium bath and the cryocoolers. As a result the original design with the copper straps was abandoned and a new more efficient coupling system was designed.

The present re-condenser and cooling loop was subsequently retrofitted into the cryostat. Instead of transporting heat between the helium bath and the cryocoolers via conduction through copper links, a helium re-condensing system is used. Helium vapor from the top of the helium tank is admitted via small diameter tubes directly to a finned copper surface where it condenses and returns as liquid via gravity to the bottom of the liquid helium tank. The finned copper condenser is bolted directly to the cryocooler flange. To remove the rated $3.0 \mathrm{~W}$ at $4.2 \mathrm{~K}$, helium flow rate to each condenser is only $0.075 \mathrm{~g} / \mathrm{s}$, or 35 liquid cc/min.; therefore the condenser can be connected to the liquid helium tank using small diameter, flexible tubes. The copper condenser can be compact. Figure 3 illustrates the scheme. 


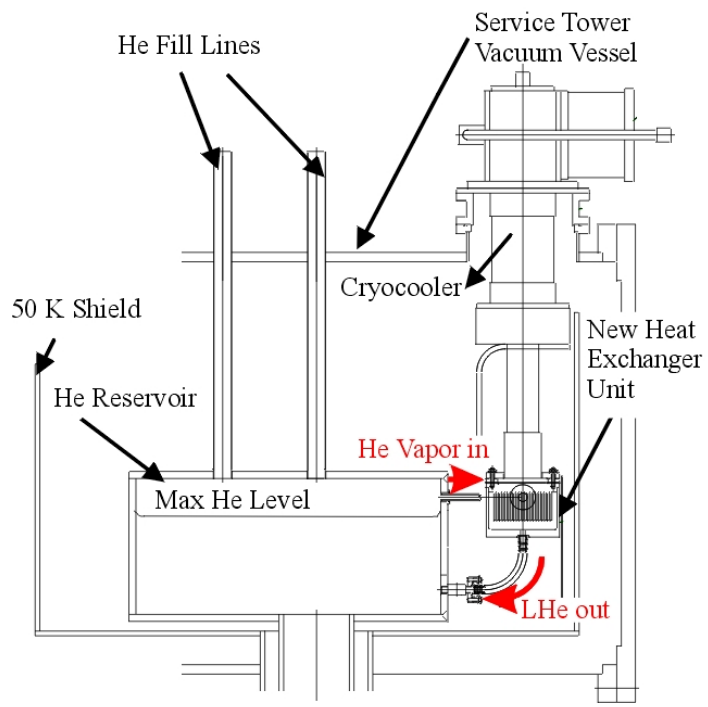

FIGURE 3. Schematic illustration of cooling method showing direction of natural-circulation helium flow

Helium gas is admitted to the top of the condenser and liquid drips down into the helium return tube. The liquid level in the condenser and return tube must be higher than the liquid level in the helium tank by enough to drive the required flow of helium. However, it should not be so high that it covers the condenser fins since that drastically reduces the heat transfer at the fins. The standard pressure drop formula, shown below, is used to predict fluid friction losses in the tubes:

$$
\Delta P=L / D f\left(\rho V^{2} / 2\right)
$$

An example calculation for two $24.5 \mathrm{~cm}$. (10 in.) of $0.53 \mathrm{~cm}$ ID tubes, one for liquid and the other for vapor is summarized below in TABLE 1. Heat input of $1.5 \mathrm{~W}$ to each cryocooler is assumed.

TABLE 1. Saturated helium properties and parameters used in an example calculation of pressure drop in the helium lines in and out of each condenser

$\begin{array}{lll}\text { Helium Properties } & \text { liquid } & \text { vapor } \\ \mathrm{T} \mathrm{K} & 4.30 & 4.30 \\ \text { enthalpy } \mathrm{J} / \mathrm{kg} & 1.05 \times 10^{4} & 3.07 \times 10^{4} \\ \text { viscosity } \mathrm{Pa} \mathrm{s} & 3.18 \times 10^{-4} & 1.24 \times 10^{-5} \\ \text { density } \rho \mathrm{kg} / \mathrm{m}^{3} & 125.4 & 16.49 \\ \text { Pressure drop } & & \\ \text { tube diameter D m } & 5.33 \times 10^{-3}(.21 \mathrm{inch}) & 5.33 \times 10^{-3}(.21 \mathrm{inch}) \\ \text { flow cross-section area } \mathrm{m}^{2} & 2.23 \times 10^{-5} & 2.23 \times 10^{-5} \\ \text { length of tubes L m } & 0.254(10 \mathrm{inch}) & 0.254(10 \mathrm{inch}) \\ \text { mass flow rate } \mathrm{kg} / \mathrm{s} & 7.40 \times 10^{-5} & 7.40 \times 10^{-5} \\ \text { volume flow rate } 1 / \mathrm{s} & 5.90 \times 10^{-4}(0.590 \mathrm{cc} / \mathrm{s}) & 4.49 \times 10^{-3}(4.49 \mathrm{cc} / \mathrm{s}) \\ \text { velocity } \mathrm{V} \mathrm{m} / \mathrm{s} & 2.64 \times 10^{-2} & 2.01 \times 10^{-1} \\ \rho V^{2} / 2 \mathrm{~Pa} & 4.38 \times 10^{-2} & 3.33 \times 10^{-1} \\ \text { Reynolds number } & 5.53 \times 10^{4} & 1.43 \times 10^{4} \\ \text { relative roughness } & 1.00 \times 10^{-3} & 1.00 \times 10^{-3} \\ \text { friction factor (turbulent flow) } & 0.039 & 0.032 \\ \text { pressure drop } \Delta \mathrm{P} \mathrm{Pa} & 0.081 & 0.502\end{array}$


The total pressure drop from TABLE 1 is only $0.58 \mathrm{~Pa}$. However, as constructed, the vapor inlet line has $6.7 \mathrm{~cm}$. of $0.533 \mathrm{~cm}$. ID tube, and $6.7 \mathrm{~cm}$. of $0.635 \mathrm{~cm}$. ID corrugated bellows for ease of construction and handling, and to accommodate thermal contraction. The liquid line has $3.8 \mathrm{~cm}$. of tube and $9.6 \mathrm{~cm}$ of bellows. In addition to fluid friction, we assume losses due to entrance and exit effects of $1.5\left(\rho \mathrm{V}^{2} / 2\right)$ for each line and, we multiply the calculated loss in the bellows by 4 to account for convoluted wall instead of a smooth tube. The total predicted pressure drop is then $2.9 \mathrm{~Pa}$, equivalent to a liquid helium head of only $2.4 \mathrm{~mm}$. This small pressure drop corresponds to a negligible difference in temperature between helium in the condenser and tank.

As an extreme example, a similar calculation indicates that a cooling loop with threemeter long tubes, each $3 \mathrm{~mm}$ ID $(0.12 \mathrm{inch})$, would require a liquid helium head difference of only $100 \mathrm{~mm}$ to transfer $1.5 \mathrm{~W}$.

\section{Design of the Helium Condenser}

The condensing surface plates or "fins" are fabricated by machining 20 equally spaced rectangular gaps $1.3 \mathrm{~mm}$-wide $(0.05 \mathrm{inch})$ and $38 \mathrm{~mm}$ deep parallel to the axis of a $76 \mathrm{~mm}$-diameter copper cylinder. This forms an array of fins of varying width. The resulting surface area for condensing is $0.18 \mathrm{~m}^{2}\left(2.0 \mathrm{ft}^{2}\right)$. FIGURE 4 shows the condensers and connecting lines prior to assembly and Figure 5 shows the condensers attached to the cryocoolers and in place in the service tower of the VENUS Cryostat.

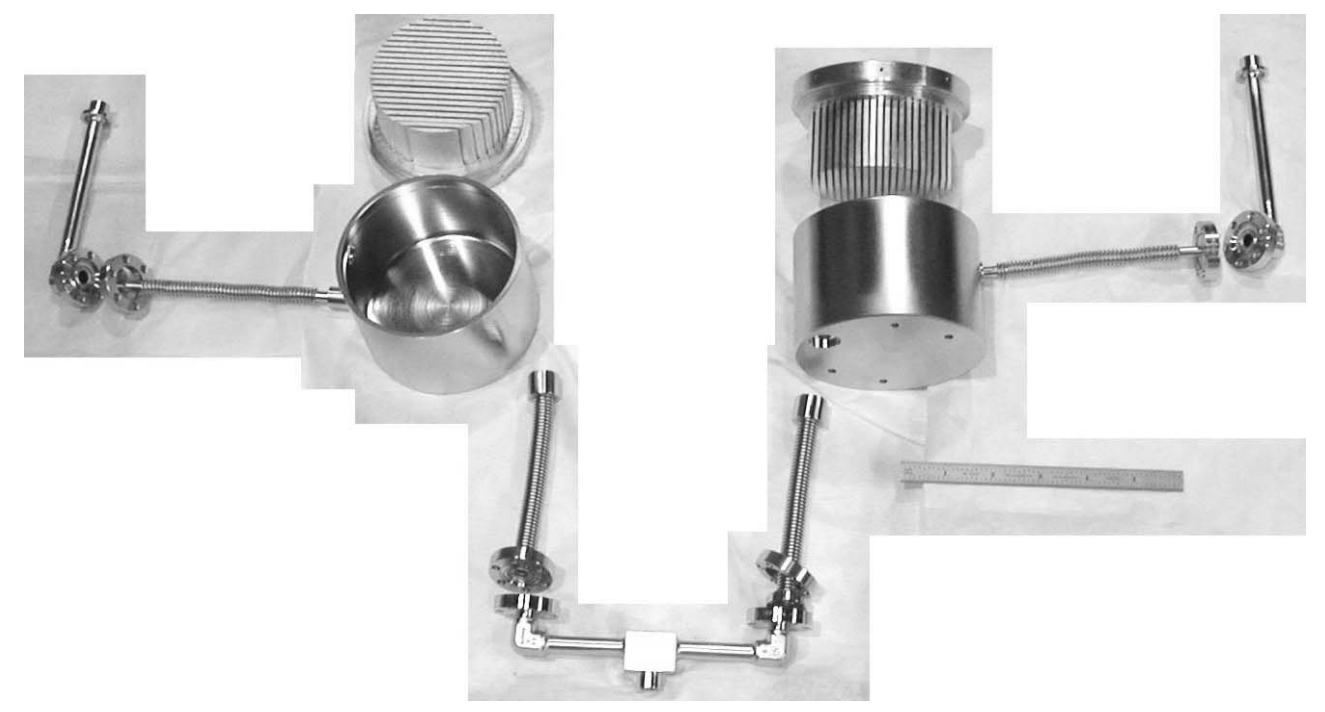

FIGURE 4. Parts of the helium condenser and piping before assembly 


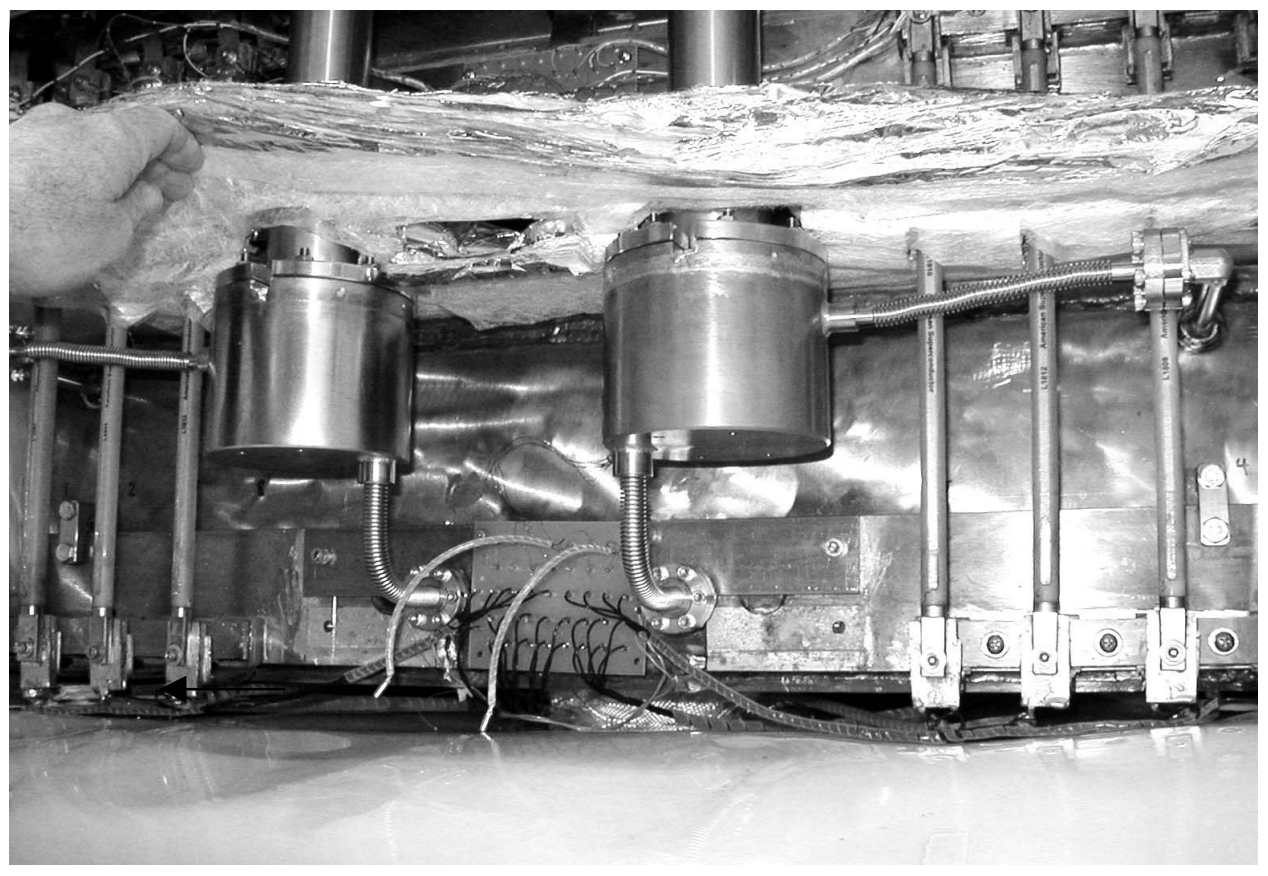

FIGURE 5. Condensers attached to cryocoolers. The upper (vapor) and lower (liquid) lines are shown. Also shown are several of the high $\mathrm{T}_{\mathrm{c}}$ current leads

\section{Heat transfer by condensation}

We use the accepted theory of Eckert [iii] in which the main resistance to heat transfer from condensing helium to a vertical flat plate is conduction across a laminar film of liquid falling downward under action of gravity. The resulting calculation gives an average heat transfer coefficient for saturated helium vapor condensing on a $3.8 \mathrm{~cm}$-high (1.5 inch) plate of $1600 \mathrm{~W} / \mathrm{m}^{2} \mathrm{~K}$. The film thickness increases with distance along the plate.

The copper is high purity ( $\mathrm{rrr}>100)$. Analysis of heat conduction [1] in the fins with helium condensing on the large-area predicts a temperature difference of only $0.02 \mathrm{~K}$ between condensing helium and base of the fins.

\section{Mechanical joint between condenser and cryocooler}

The mating surface of both condenser and cryocooler are tinned with indium and an indium foil gasket, $0.07 \mathrm{~mm}$ (.005inch) thick, is inserted. Additionally, a system was designed to achieve a larger clamping force between the condenser and the 6-mm-thick copper flange of the cryocooler second stage than is achievable with the usual six $5-\mathrm{mm}$ screws. FIGURE 6 shows a drawing of this design. 


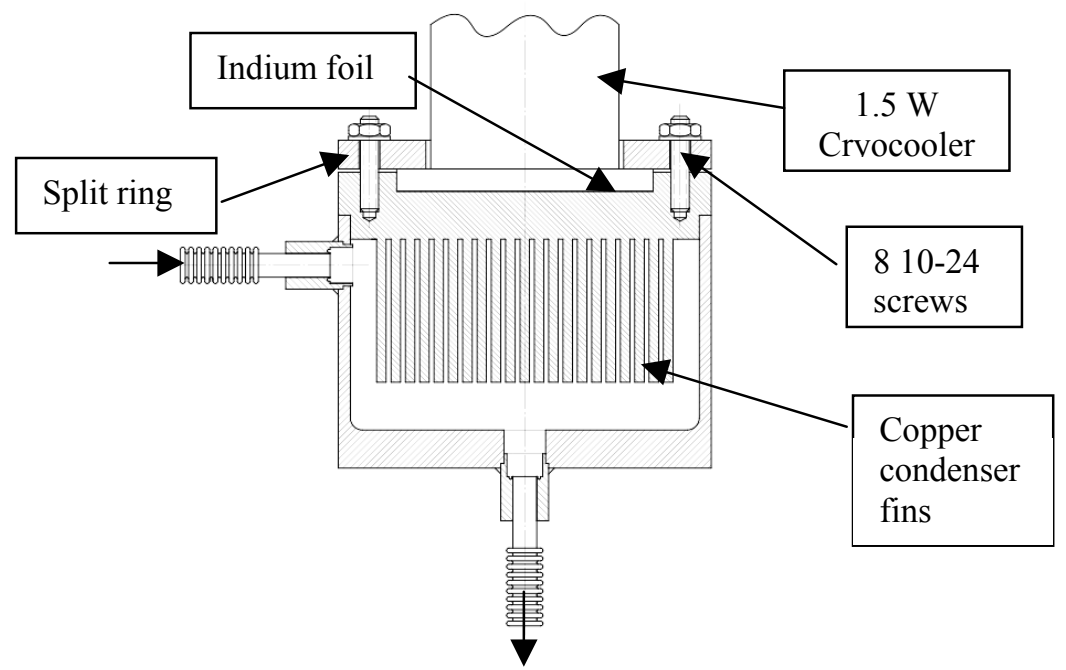

FIGURE 6. Design of system for clamping condenser to cryocooler

Thermal conductivity across a similar joint, without tinned copper surfaces and with less clamping force indicated thermal conductivity of about $0.12 \mathrm{~K} / \mathrm{W}$ [iv] which would indicate a temperature drop of $0.18 \mathrm{~K}$ for $1.5 \mathrm{~W}$.

\section{PERFORMANCE AND CONCLUSIONS}

The VENUS cryogenic system has been operating continuously for more than 11 months. With magnets on, temperature of the helium bath is $4.35 \mathrm{~K}$ as measured by both temperature sensors and pressure. Measurements show that the helium bath temperature is less than $0.05 \mathrm{~K}$ higher than the temperature of the cryocooler second stage. Since $\Delta \mathrm{T}$ of only $0.02 \mathrm{~K}$ is predicted for the condenser and tubing loop, we surmise that the $\Delta \mathrm{T}$ across the joint between the cryocooler and the condenser is about $0.03 \mathrm{~K}$.

This method of transferring heat between a liquid helium bath and a source of cooling, with very small temperature drop, is simple, very effective, and versatile. It allows freedom to locate the cryocooler some distance from a helium bath using small diameter flexible tubes.

In addition to the static heat load and the heat generated by the current leads, some of the Bremsstrahlung produced by the hot electrons in the plasma chamber is adsorbed in the cryostat. VENUS currently operates with $2000 \mathrm{~W}$ of $18 \mathrm{GHz}$ RF power. Much of that power goes into heating the electrons in the plasma, some of which reach one or more $\mathrm{MeV}$ in energy. When these electrons impact the wall they generate Bremsstrahlung. The amount of heat deposited in the $4.5 \mathrm{~K}$ parts of the cryostat depends on the source tuning. With the source carefully tuned and stable plasma conditions, the additional heat load is on the order of $300 \mathrm{~mW}$ for $2000 \mathrm{~W}$ of RF. A $10 \mathrm{~kW} 28 \mathrm{GHz}$ gyrotron will be installed on VENUS in December and to cope with the additional Bremsstrahlung heating, a third 1.5 $\mathrm{W}$ cryocooler will be installed The revised system also makes it possible to use the first stage of two of the cryocoolers to eliminate the need for liquid nitrogen cooling in the future. 


\section{ACKNOWLEDGMENTS}

The superconducting magnet coil assembly and original cryostat were constructed by Wang, NMR, Inc., Livermore, CA

\section{REFERENCES}

i. C. E. Taylor, S. Caspi, M. Leitner, S. Lundgren, C. Lyneis, D. Wutte, S.T. Wang, J.Y. Chen, Magnet System for an ECR Ion Source, IEEE Transactions on Applied Superconductivity, 10(1), p. 224 (2000).

ii. M.A. Leitner, C.M. Lyneis, D. Wutte, C.E. Taylor and S.R. Abbott, Physica Scripta,T92, pp.171-173 (2001).

iii. E. R. G. Eckert, Introduction To Transfer of Heat and Mass, McGraw-Hill, 1950 .

iv. Jon Zbasnik, Lawrence Berkeley National Laboratory, private communication, 2003. 